\title{
AMBIENTE INSTITUCIONAL E EMPREENDEDORISMO NO BRASIL: INTER-RELAÇÕES NO SÉCULO XXI
}

\section{INSTITUTIONAL ENVIRONMENT AND ENTREPRENEURSHIP IN BRAZIL: INTER-RELATIONS IN THE XXI CENTURY}

\author{
Michelle Oliveirado Espírito Santo Corsino \\ Universidade Federal do Mato Grosso do Sul - UFMS \\ ir.michelle@hotmail.com \\ Milton Augusto Pasquotto Mariani \\ Universidade Federal do Mato Grosso do Sul - UFMS \\ miltmari@terra.com.br
}

Submissão: 07/05/2019

Aprovação: 08/07/2019

\begin{abstract}
RESUMO
Partindo dos pressupostos balizados pela Nova Economia Institucional acerca das instituições e do ambiente institucional e dos dados coletados pela pesquisa Global Entrepreneurship Monitor (GEM), nos anos 2000 e 2017, o presente ensaio teórico objetiva apresentar evidências das inter-relações existentes entre o ambiente institucional e o empreendedorismo no Brasil. Dessa forma, utilizando-se de uma abordagem qualitativa, são apresentados alguns elementos do ambiente institucional brasileiro que têm favorecido o empreendedorismo e outros que têm limitado a criação e manutenção de novos empreendimentos no país, no século XXI. Nesta perspectiva, a partir da lente da teoria institucional e da teoria do empreendedorismo, o presente estudo teórico demonstra o papel das instituições enquanto "regras do jogo" (políticas, sociais e legais) que influenciam diretamente na evolução do fenômeno do empreendedorismo, bem como proporciona uma reflexão no que tange ao ambiente institucional brasileiro, demonstrando até que ponto ele promove um cenário propício à iniciativa econômica de criar empreendimentos.
\end{abstract}

Palavras-chave: Nova Economia Institucional. Ambiente Institucional Brasileiro. Empreendedorismo. Século XXI.

\begin{abstract}
Based on the assumptions made by the New Institutional Economics about institutions and the institutional environment and the data collected by the Global Entrepreneurship Monitor (GEM), in the years 2000 and 2017, this theoretical essay aims to present evidence of the interrelationships between the institutional environment and entrepreneurship in Brazil. Thus, using a qualitative approach, some elements of the Brazilian institutional environment that have favored entrepreneurship and others that have limited the creation and maintenance of
\end{abstract}


new enterprises in the country in the XXI century are presented. In this perspective, from the lens of institutional theory and entrepreneurship theory, the present theoretical study demonstrates the role of institutions as "rules of the game" (political, social and legal) that directly influence the evolution of the phenomenon of entrepreneurship, as well as provides a reflection on the Brazilian institutional environment, demonstrating the extent to which it promotes a scenario conducive to economic initiative to create entrepreneurship.

Keywords: New Institutional Economy. Brazilian Institutional Environment. Entrepreneurship. XXI Century.

\section{INTRODUÇÃO}

É esperado que o ambiente institucional minimize os custos envolvidos nas transações e gere condições propícias à iniciativa econômica de abertura de novos empreendimentos nos países.

Coase (1937), em sua obra seminal "The Natureza of the Firm" aponta que a firma/organização consiste no sistema de relações que entra em existência quando a direção de recursos depende de um empreendedor. Neste contexto, o mecanismo de preços apresentase como elemento insuficiente para redução dos custos de transação, tornando-se mais vantajoso para a economia, a criação de novos negócios que captem as oportunidades de geração e distribuição de recursos. Em consonância com este pensamento, North (1990) acrescenta que os estímulos oferecidos pela matriz institucional, nas sociedades, farão surgir múltiplas organizações que atuarão na busca de diversos objetivos.

As instituições, na esteira de North (1991), são entendidas como as regras formais (constituições, leis e direitos de propriedade) e informais (sanções, tabus, costumes, tradições e códigos de conduta) que governam as relações entre os indivíduos nas sociedades e, portanto, influenciam, sobremaneira, no desenvolvimento econômico dos países. O autor afirma, ainda, que a principal função das instituições é criar ordem e reduzir as incertezas. Sob esta lente, os arranjos institucionais podem ser entendidos pela sua capacidade de influenciar positiva ou negativamente a economia, impactando no surgimento ou extinção de organizações econômicas.

$\mathrm{O}$ fato de estimular ou retrair o surgimento de novos empreendimentos apresenta relação direta com a forma, na qual o ambiente institucional está configurado. Neste sentido, alguns pontos relevantes precisam ser examinados em relação a esse ambiente:

- Se reduz ou não os custos envolvidos na realização de contratos;

- Se facilita ou dificulta a realização das transações no mercado;

- Se promove ou não um cenário propício ao investimento;

- Se estimula ou não os indivíduos a assumir riscos de criar empreendimentos, promovendo a atividade econômica.

Diante deste cenário, North (1991) ressalta que as instituições representam, ao longo da história, a manutenção da ordem e a redução das incertezas nas sociedades. Com efeito, elas restringem o conjunto de alternativas e oportunidades disponíveis aos agentes econômicos, favorecendo, ou não, a redução dos custos de transação e a lucratividade.

Com base na noção de "incerteza", Knight (1964) introduz o conceito de "julgamento", com o intuito de conectar a incerteza ao lucro e a firma/organização. Esse julgamento requer que indivíduos que não tenham medo de correr riscos deem início a uma firma e tomem decisões sobre o emprego de recursos.

Neste segmento, Holcombe (2003) assevera que as oportunidades são reveladas por meio da descoberta empreendedora, e são as instituições que tornam possível essa descoberta. 
Elas podem promover ou não um contexto favorável para o reconhecimento de possíveis oportunidades, além de favorecer ou inibir o custo de criar um empreendimento para apropriar o valor econômico vislumbrado nestas oportunidades.

No Brasil, a abordagem do empreendedorismo dentro de um contexto institucional é possível a partir do seu reconhecimento como um fenômeno social e não apenas econômico. De acordo com Salim e Silva (2010), o empreendedorismo é reconhecido, no Brasil, como promotor de desenvolvimento econômico e social, pois gera emprego e renda, cria produtos inovadores, atua na busca de soluções para questões sociais e estimula programas governamentais, favorecendo o desenvolvimento local e regional.

Dessa forma, entende-se que tanto as instituições formais, quanto as informais podem legitimar o empreendedorismo como uma atividade de valor social, ou ao contrário, limitar e desencorajar o potencial empreendedor.

Cumpre mencionar que a Pesquisa GEM (Global Entrepreneurship Monitor) é referência no debate sobre empreendedorismo no Brasil e no mundo, constituindo-se em um estudo completo sobre o panorama atual deste tema; sendo utilizada para análises comparativas, tanto em relação a dados entre os países participantes, quanto a indicadores de edições anteriores. No Brasil, é desenvolvida desde o ano 2000 pelo Instituto Brasileiro de Qualidade e Produtividade (IBQP), com apoio do SEBRAE, a fim de, favorecer uma melhor compreensão acerca do perfil empreendedor do cidadão brasileiro, bem como contribuir para o desenvolvimento da sociedade, da economia e das políticas públicas. No que concerne aos postulados de GEM (2017, p. 6), o objetivo central da realização da pesquisa é:

[...] aprofundar a compreensão sobre o papel que a atividade empreendedora cumpre para o desenvolvimento econômico e social dos países, e por sua vez, com base nos conhecimentos obtidos permitir que os responsáveis por políticas e programas voltados ao empreendedorismo possam cada vez mais aperfeiçoá-los com foco nas realidades identificadas e apreendidas por meio dos dados e informações produzidos.

Neste contexto, o presente estudo teórico analisa o panorama do empreendedorismo brasileiro no século XXI, a partir dos dados apresentados pela pesquisa GEM nos anos 2000 (ano inicial da realização da GEM no Brasil) e 2017 (ano mais recente da divulgação dos dados da GEM), com o intuito de identificar quais elementos do ambiente institucional brasileiro têm favorecido o empreendedorismo e quais elementos têm atravancado a criação e manutenção de novos empreendimentos no país, utilizando a lente da teoria institucional e da teoria do empreendedorismo.

\section{Ambiente Institucional: deslindando conceitos}

É relevante considerar as instituições como ponto de partida para o entendimento de qualquer cenário econômico, político e social, pois além de serem as "regras do jogo" (NORTH, 1991), são elas e não os indivíduos que apresentam caráter estável e permanente ao longo de extensos períodos.

Assim, o papel das instituições é gerar ordem e estabilidade nos processos sociais, uma vez que tornam os comportamentos dos agentes mais previsíveis, sinalizando como devem ser suas ações e estabelecendo canais de intercâmbio entre eles. Além disso, elas apresentam mecanismos de coordenação que tornam viável o funcionamento de uma economia pela divisão do trabalho e cooperação.

North (1991) afirma que as instituições são as restrições arquitetadas pelos indivíduos, que dão forma à sua interação, portanto, depreende-se que as decisões econômicas, as motivações e expectativas dos indivíduos em relação ao aproveitamento de oportunidades e 
abertura de novos negócios encontram-se, sempre, influenciadas, limitadas e moldadas pelas instituições.

Nesse segmento, Williamson (2000) pondera que as instituições objetivam reduzir os custos na realização de contratos, garantir o direito de defesa de propriedade, facilitar a realização das transações e gerar um ambiente favorável ao investimento e a propensão para assumir riscos com o intuito de criar novos empreendimentos, promovendo, com isso, a atividade econômica em uma determinada sociedade.

North (1991) destaca que o conjunto de instituições forma o ambiente institucional das sociedades. Segundo o autor, este ambiente deve fornecer a estrutura de incentivos para a economia e favorecer o desenvolvimento do Estado, para assumir a proteção e a execução dos direitos de propriedade de forma impessoal.

Dessa forma, o ambiente institucional, segundo Williamson (2000), é sustentado pela cultura dos países, traduzida pelas crenças e valores, que formam as regras formais, as quais definem as normas de conduta e as leis, a configuração das estruturas de independência do judiciário e defesa dos direitos à propriedade, bem como as formas de governança e estabelecimento de contratos nas organizações. Essas regras governam o comportamento econômico individual e estruturam as relações sociais, estabelecem e conduzem as bases da produção, troca e distribuição dentro de uma economia capitalista.

No ambiente institucional emergem as Organizações, que são entendidas por North (1991) como entidades que reúnem indivíduos para um determinado fim, interagindo entre si e com a matriz institucional para reduzir os custos de transação.

A presente abordagem justifica-se pela carência de estudos na literatura sobre o reconhecimento da inter-relação entre o ambiente institucional e a atividade empreendedora no Brasil, caracterizada pelo surgimento de novas organizações econômicas.

É importante trazer à baila a contribuição dos estudiosos Robert Hall e Charles Jones (1999), os quais realizaram um estudo nessa linha de pensamento, utilizando uma amostra de vários países. Concluíram que o desempenho econômico de longo prazo de um país é determinado pelas instituições que compõem o ambiente econômico, no qual indivíduos e empresas fazem investimentos para criar, transferir ideias e produzir bens e serviços.

A partir de uma análise empírica, Hall e Jones (1999) compreenderam que as instituições relevantes para o empreendedorismo são: o imposto (o sistema tributário influencia na escolha do indivíduo em se tornar um empreendedor, pois o imposto reduz os ganhos de abrir novos negócios); a legislação do mercado de trabalho (as regulamentações trabalhistas aumentam os custos esperados de abrir e fazer crescer uma firma, adicionando uma barreira ao empreendedorismo); e o mercado de capitais (um mercado de capitais bem estruturado pode contribuir para fomentar a inovação e financiar firmas empreendedoras). Além destas três variáveis institucionais, o ambiente jurídico também apresenta um grande impacto sobre o empreendedorismo, uma vez que influencia na complexidade dos contratos de investimento e no sucesso destes investimentos, definindo os direitos de propriedade.

\section{Empreendedorismo: contexto histórico}

Um dos primeiros pensadores da atividade empreendedora foi o economista Richard Cantillon. De acordo com sua definição, o empreendedor era alguém que comprava matéria prima, transformava em um produto acabado a fim de revendê-lo por um preço maior, ou seja, "alguém que assumia riscos, aproveitando oportunidades, com o objetivo de obter lucros" (CANTILLON apud MASIERO, 2009, p. 406).

No século XVII surgiu a relação entre "assumir riscos" e o empreendedorismo. Emergiu, também, a diferenciação entre o fornecedor do capital, o capitalista, e aquele que assume riscos, o empreendedor. Ocorre, todavia, que foi somente no século XVIII, que 
capitalista e empreendedor foram complemente diferenciados, certamente em decorrência do início da industrialização.

Uma pertinente definição da palavra "empreendedor" foi elaborada no início do século XIX pelo economista francês J. B. Say. Segundo essa definição, o “[...] empreendedor é aquele que transfere recursos econômicos de um setor de produtividade mais baixa para um setor de produtividade mais elevada e de maior lucro" (BRITTO; WEVER 2003, p. 17).

No tocante ao século XX, foi apresentada a definição do economista moderno Joseph Schumpeter, o qual considera que "[...] o empreendedor é uma pessoa que destrói a ordem econômica existente, introduzindo novos produtos e serviços, criando novas formas de organização e explorando novos materiais" (SCHUMPETER, 1949 apud SALIM E SILVA 2010, p.8).

$\mathrm{Na}$ ótica de Joseph Schumpeter, o empreendedorismo está na percepção e aproveitamento de novas oportunidades de negócios criadas a partir do desenvolvimento de novas formas de utilização dos recursos disponíveis. Sendo assim, os empreendedores são responsáveis por estimular a demanda de mercado, criando um desequilíbrio adicional ao sistema econômico. Entretanto, o termo não se limita ao indivíduo que vê e explora as oportunidades, mas também aquele que cria oportunidades e as explora (MASIERO, 2009).

Com efeito, de acordo com Salim e Silva (2010, p.6), o empreendedorismo "[...] é algo que o ser humano já pratica a muitos séculos". As formas de empreendedorismo mudaram ao longo do tempo, todavia a essência continua a mesma. Sempre existiram pessoas proativas, visionárias, que souberam (e sabem) aproveitar as oportunidades; sem receio de correr riscos calculados.

Bernardi (2003, p. 64) considera que a ideia de um empreendimento surge "[...] da observação, da percepção e análise das atividades, tendências e desenvolvimentos, na cultura, na sociedade, nos hábitos sociais e de consumo". Tal reflexão denota que o empreendedor deve possuir um profícuo conhecimento de diversos cenários, a fim de interagir com um ambiente institucional dinâmico e desafiador.

A diferença entre o empreendedor do passado e o de hoje é o considerável volume de informações disponíveis e acessíveis em tempo real, além das novas tecnologias que agilizam e disseminam os processos.

Valendo-se das contribuições de Peter Drucker (1987, p.39), os empreendedores são agentes de inovação, haja vista que, para o estudioso, a ideia de inovação é compreendida como o "[...] ato que contempla os recursos com a nova capacidade de criar riquezas". Portanto, pode-se considerar que a essência do empreendedor é a sua capacidade criativa. Com efeito, o empreendedor possui espírito vanguardista e fomenta a visualização de mudança no status quo, favorecendo a materialização de oportunidade para emergir o novo e o diferente, potencializando a geração riquezas.

Notadamente, Peter Klein (2015) introduz, neste contexto, a Escola Austríaca, conjugando a Teoria da Firma com o Empreendedorismo. Segundo o autor, o empreendedorismo é indissociável do gerenciamento de ativos e do controle de recursos. Dessa forma, pode-se compreender que os empreendedores desempenham a função de organizar bens de capital que são heterogêneos, pois se os bens de capital fossem homogêneos, as ações dos empreendedores teriam caráter trivial e a própria teoria da firma seria irrelevante. $\mathrm{O}$ autor reconhece o relevante papel de Coase para a Teoria da Firma e dos Contratos. Funde os custos de transação de Williamson, a incerteza e a inovação de Knight, a teoria do capital, o dinamismo e o subjetivismo da Escola Austríaca, apresentando uma nova perspectiva, colocando o empreendedor como figura de destaque nos processos do mercado.

Klein (2015) baseado nos estudos de Shane (2000) - A General Theory of Entrepreneurship - assevera que a identificação de oportunidades envolve não somente habilidades técnicas, como análise financeira e pesquisa de mercado, mas também formas 
mais intangíveis de criatividade, construção de equipes, resolução de problemas e liderança. Seguindo a linha de reflexão proposta pelo autor, o valor pode ser criado não somente pelo início de novas atividades, mas pelo melhoramento da operação de atividades existentes, que podem incluir: a criação de uma nova firma, o início de um novo acordo de negócios, a introdução de um novo produto ou serviço, ou o desenvolvimento de um novo método de produção.

\section{Ambiente Institucional e Empreendedorismo no Brasil}

Dentro de uma abordagem qualitativa, a presente pesquisa caracteriza-se como bibliográfica, pois foi desenvolvida a partir de material já elaborado. De acordo com as etapas propostas por Marconi e Lakatos (2010), após a escolha do tema, elaboração do plano de trabalho, identificação e localização do objeto de estudo, iniciou-se a compilação dos dados coletados nas edições do ano 2000 e 2017, da pesquisa GEM.

A pesquisa GEM foi realizada pela primeira vez no Brasil no ano 2000, com a utilização do modelo internacional (consorciado entre o Babson College e a London Business School), sendo necessárias pequenas adaptações à realidade brasileira. Foram entrevistados 55 informantes-chave (especialistas no assunto) de diversos Estados; além destes, foram entrevistadas 2.000 pessoas da população adulta, com a utilização de um questionário padrão, cujos resultados forneceram dados para o cálculo das taxas de empreendedorismo no Brasil; os dados foram incorporados à análise internacional, sendo tabulados e analisados estatisticamente, parte no Brasil e parte em Londres.

Os resultados referentes ao contexto do ambiente institucional foram os seguintes:

- Os fatores que mais se destacaram como determinantes ao impulso empreendedor no Brasil foram: políticas governamentais, educação e acesso ao capital;

- O Brasil, no ano 2000, representou uma contradição da hipótese original da pesquisa GEM - que afirma que o crescimento da atividade empreendedora impulsiona o crescimento econômico - pois, enquanto as taxas do empreendedorismo situaram-se nos patamares mais altos, o PIB do país foi o penúltimo dos países pesquisados, sendo superior apenas ao PIB da Índia. O Brasil, juntamente com a Índia, foi classificado como um país cuja economia ainda contava com uma participação elevada de atividade agrícola;

- Tanto na opinião dos especialistas quanto da população, a capacidade dos brasileiros em perceber oportunidades, iniciar e administrar negócios era bastante limitada. As atividades empreendidas, revelaram que o empreendedor brasileiro não estava, de fato, explorando oportunidades com potencial de crescimento, e sim buscando formas possíveis de geração de renda (empreendedorismo por necessidade);

- Ao avaliar os demais fatores que dizem respeito à educação, políticas e programas, os especialistas afirmaram que o Brasil oferecia poucas condições de suporte e estímulo à iniciativa empreendedora e que todas essas áreas demandam intervenções, tanto do setor público quanto do privado;

- As atitudes culturais que prevaleciam em relação ao empreendedorismo no Brasil eram conservadoras. De acordo com os especialistas, culturas com valores conservadores quanto ao risco, ao novo e ao erro são pouco propícias ao empreendedorismo.

- O acesso ao capital constituía um dos maiores obstáculos à ação empreendedora no ano 2000. Apesar da disponibilidade do capital, o acesso a ele era fator restritivo. O principal entrave era a pouca flexibilidade do sistema financeiro, incluindo instituições governamentais, no tocante à avaliação e coparticipação no risco. A exigência de garantias reais afastava a busca efetiva de capitalização de projetos empreendedores; 
- Os impostos eram considerados altos, constituindo um aspecto desencorajador para a expansão de negócios;

- O apoio governamental para as pequenas empresas era visto como ineficiente: os programas fracassavam na tentativa de fornecer suporte, e também não eram suficientemente divulgados.

Em 2017 a pesquisa GEM alcançou a sua "maioridade" no Brasil, pois completou 18 anos ininterruptos da sua realização, retratando as características dos empreendedores brasileiros e seus negócios. Neste ano foram entrevistadas 2000 pessoas em todo o território nacional, buscando identificar as atitudes, atividades e aspirações da população em relação ao empreendedorismo. Em 2017 foram entrevistados, também, 60 especialistas. Os especialistas compreenderam profissionais do setor público ou privado, estudiosos e empreendedores com elevado grau de experiência ou conhecimento acerca de determinadas condições que afetam o empreendedorismo (GEM, 2017).

Na pesquisa GEM 2017, a análise dos resultados foi subdividida em dois grupos: "fatores limitadores" e "fatores favoráveis" ao surgimento e manutenção de novos empreendimentos no Brasil.

Dentre os fatores limitadores destacam-se:

- As políticas e programas governamentais. Os especialistas enfatizaram que são necessárias iniciativas mais acuradas para promoção da ação empreendedora. Foi apontada, por exemplo, a necessidade de melhoria em áreas como a tributária e de desburocratização;

- O apoio financeiro. A maioria dos especialistas consideram que as dificuldades associadas à disponibilização e acesso a recursos financeiros para o fomento das atividades empreendedoras ainda se constituem como fatores relevantes a serem melhorados;

- O contexto político e o clima econômico. Nos anos recentes é a primeira vez que esse fator aparece com destaque, não obstante as explicações são óbvias e decorrentes da crise política que se asseverou em 2016 e 2017 com evidentes consequências para o animus empreendedor do brasileiro.

Dentre os fatores favoráveis destacam-se:

- Aspectos relacionados às características da população brasileira, sua capacidade de realização e superação de desafios. Este item também faz referência à diversidade étnica e cultural que, para os especialistas, é motivo de inspiração e esperança para quem decide realizar uma atividade empreendedora;

- Poucas barreiras para a abertura de novos negócios, situação que favorece, também, o acesso aos mercados consumidores.

- Alguns programas governamentais de incentivo a abertura de pequenos negócios, como o MEI (Microempreendedor Individual) e a participação das Micro e Pequenas Empresas nas Compras Públicas.

Ao comparar o ambiente institucional predominante no ano 2000 com o apresentado no ano de 2017, percebe-se uma discreta evolução, na qual os fatores favoráveis à abertura e manutenção de novos empreendimentos se sobressaíram em relação aos fatores limitadores.

Dessa forma, merecem destaque: a evolução do empreendedorismo por oportunidade em detrimento do empreendedorismo por necessidade (geração de renda); melhorias nas condições de suporte e estímulo à iniciativa empreendedora (embora ainda exista um longo caminho, neste sentido, a ser percorrido pelo setor público e privado); melhorias nas políticas governamentais (MEI), educação empreendedora (Universidades) e acesso ao capital (linhas de créditos acessíveis aos pequenos empreendimentos); evolução da mentalidade dos brasileiros em relação a valores conservadores (quanto ao risco, ao novo e ao erro que atravancavam iniciativas empreendedoras); as novas políticas fiscais com a introdução do 
Programa Simples Nacional, o qual reduz e unifica a carga tributária dos micro e pequenos empreendimentos em uma cota mensal única.

Apesar desta discreta evolução, o contexto político e o clima econômico nos anos mais recentes, particularmente 2016 e 2017, apresentam-se como os principais fatores limitadores da ação empreendedora no país. Diante deste cenário apresentado, cumpre destacar que a crise política neste período é apontada como a principal causa desmotivadora para o animus do empreendedor brasileiro (GEM, 20017).

\section{CONSIDERAÇÕES FINAIS}

O presente ensaio teórico, embasado na teoria institucional de Coase, Williamson e North e na teoria do empreendedorismo de Schumpeter, Drucker, Knight, Klein apresentou elementos relevantes acerca das inter-relações entre o ambiente institucional e a atividade empreendedora.

Foi realizada uma pesquisa bibliográfica que propiciou a comparação entre o ambiente institucional brasileiro nos anos 2000 e 2017, utilizando dados da pesquisa GEM, a fim de apontar os principais fatores limitadores e favoráveis ao empreendedorismo no Brasil. A análise destes dois momentos objetivou construir um panorama da evolução, no século XXI, da ação empreendedora no Brasil.

Ao final do estudo, identificou-se uma discreta evolução dos elementos favoráveis ao empreendedorismo no ambiente institucional brasileiro. No entanto, os especialistas (GEM, 2017) apontaram algumas ações que ainda precisam ser realizadas pelas instituições brasileiras para impulsionar o surgimento e a manutenção de novos empreendimentos: desburocratização efetiva; implementação de política de desenvolvimento para os pequenos negócios; acompanhamento dos efeitos da reforma trabalhista no contexto de criação de novos empreendimentos; investimento em capacitação; apoio às organizações que já fomentam o empreendedorismo (Sebrae, Endeavor, Senac, Anprotec, entre outras.); incentivo ao empreendedorismo nas mídias de massa: compartilhamento de experiências e de casos sucesso e insucesso por meio de programas televisão, propagandas, entre outros; aproximação da atividade empreendedora praticada intuitivamente com ambientes escolares e com a universidade; aproximação entre pesquisa, boas tecnologias e novos empreendedores; e, por fim, melhorias nas condições de financiamento que garantam maior segurança na manutenção e expansão dos empreendimentos.

Portanto, diante das inter-relações encontradas entre o ambiente institucional e o empreendedorismo no Brasil, sugere-se, para pesquisas futuras, o estudo comparativo destas inter-relações entre as regiões brasileiras, com o intuito de identificar quais apresentam condições mais favoráveis ao surgimento de novos empreendimentos.

\section{REFERÊNCIAS}

ASSOCIAÇÃO BRASILEIRA DE NORMAS TÉCNICAS - ABNT. NBR 6022: artigo em publicação periódica científica impressa-apresentação. Rio de Janeiro, 2003.

BERNARDI, Antônio Luiz. Manual de Empreendedorismo e Gestão: Fundamentos, estratégias e dinâmicas. São Paulo: Atlas, 2003.

BRITTO, Francisco; WEVER, Luiz. Empreendedores brasileiros: vivendo e aprendendo com grandes nomes. Rio de Janeiro: Campus, 2003.

COASE, R. H. The Nature of the Firm. Economica, pp. 386-405, nov. 1937.

The Problem of Social Cost. Journal of Law and Economics, pp. 1-44, oct.

1960. 
DRUCKER, Peter F. Inovação e espírito empreendedor - Entrepreneurship: prática e princípios. 2.ed. São Paulo: Pioneira, 1987.

GLOBAL ENTREPRENEURSHIP MONITOR (GEM). Empreendedorismo no Brasil: 2000. Simara Maria de Souza Silveira Greco et. al.Curitiba: IBPQ, 2000.

. Empreendedorismo no Brasil: 2017. Simara Maria de Souza Silveira Greco et. al.Curitiba: IBPQ, 2017.

HALL, Robert E.; JONES, Charles I. Why do some countries produce so much more output per worker than others?. The Quarterly Journal of Economics, Vol. 114, No. 1 (Feb., 1999), pp. 83-116.

HOLCOMBE, Randall G. The origins of entrepreneurial opportunities. The Review of Austrian Economics, v. 16, n. 1, p. 25-43, 2003.

KLEIN, Peter G. O Capitalista e o Empreendedor: Ensaios sobre Organizações e Mercados. Tradução: Cláudio A. Télles-Zepeda. São Paulo: Instituto Von Mises Brasil. Brasil, 2015. 272p.

KNIGHT, Frank H. Risk, Uncertainty and Profit. Boston: Houghton Mifflin,[original 1921] 1964.

LAKATOS, Eva Maria; MARCONI, Marina de Andrade. Fundamentos de metodologia cientifica. 7. ed. São Paulo: Atlas, 2010.

MASIERO, Gilmar. Administração de Empresas: Teoria e funções com exercícios e casos. 2 ed. São Paulo: Saraiva, 2009.

NORTH, D. C. Institutions, Institutional Change and Economic Performance. Cambridge University Press, Cambridge, 1990.

. Institutions. The Journal of Economic Perspectives, pp. 97-112, 1991.

SALIM, César Simões; SILVA, Nelson Caldas. Introdução ao empreendedorismo: despertando a atitude empreendedora. Rio de Janeiro: Elsevier, 2010.

WILliamsON, O. E. The New Institutional Economics: Taking Stock, Looking Ahead. Journal of Economic Literature, pp. 595-613, sep. 2000.

. The theory of the firm as governance structure: from choice to contract.

Journal of Economic Perspective, v.16, n.3, summer 2002, p. 171-195. 